Advances in Cement Research

Pozzolanic reaction rate of fluid catalytic cracking catalyst residue (FC3R) in cement pastes

Payá, Monzó, Borrachero and Velázquez

\title{
Pozzolanic reaction rate of fluid catalytic cracking catalyst residue (FC3R) in cement pastes
}

\section{Jordi Payá}

Professor in Building Materials Chemistry, Department of Construction Engineering, Universitat Politècnica de València, València, Spain José M. Monzó

Professor in Building Materials Chemistry, Department of Construction Engineering, Universitat Politècnica de València, València, Spain

\section{María V. Borrachero}

Assistant Professor, Department of Construction Engineering, Universitat Politècnica de València, València, Spain

Sergio Velázquez

Professor, Structural and Construction Department, Panamerican

University, Zapopan, México

Fluid catalytic cracking catalyst residue (FC3R) is a waste material generated in the petroleum industry. Previous research has shown that FC3R exhibits excellent pozzolanic properties in Portland cement mixtures. The pozzolanic activity of FC3R was studied by means of thermogravimetric analysis (measurement of lime fixation) and cold hydrochloric acid treatment (quantification of FC3R reacted). A water/binder ratio of 0.40 was used in the study in the preparation of a control paste (without spent catalyst) and a $15 \%$ substituted FC3R paste. The selected curing temperatures were 20 and $40^{\circ} \mathrm{C}$ and several curing times were tested. The amount (grammes) of fixed lime by gramme of reacted catalyst indicated that approximately one part lime is chemically combined with 2.3 parts of spent catalyst. The combination of both study techniques allows determination of the optimal dosage in order to maximise use of this excellent pozzolan.

\section{Introduction}

The increasing generation of waste materials means alternatives need to be found for their final disposal. Stabilisation by means of hydraulic binders such as Portland cement has shown excellent results, and many types of materials have been confined using this technique. Furthermore, if those waste materials exhibit pozzolanic properties, they can help to improve binder properties such as mechanical strength, durability and shrinkage, among others. For residues that are generated in large quantities, it is desirable to add the largest possible amount while maintaining the basic properties of the final product. However, if residue generation is not large and/or if its pozzolanic activity is very high, dosage of the addition should be optimised. That is, for materials with high pozzolanic activity, the consumption of lime (which is generated by the cement hydration process) increases considerably, up to the level of total consumption, meaning that excess mineral addition behaves as inert.

Fluid catalytic cracking catalyst residue (FC3R, also called spent catalyst) is generated as a waste product in the petroleum refinery, specifically in the fluidised bed catalytic cracking process. At the end of 2010, some 400 catalytic cracking units were in operation, having a total processing capacity of 12.4 million barrels of feedstock per day. Typical consumption of catalyst is around $0.45 \mathrm{~kg} / \mathrm{m}^{3}$ of petroleum, so global production of spent catalyst would be slightly less than $1000 \mathrm{t} /$ day (Meyers, 1996). Hsu et al. (2011) reported similar values for 2011, in the range of 900000 to 1400000 t, while Antiohos et al. (2006) indicated that the amount produced in 2005 was 1200000 t. Comparing these amounts with estimates of global production of byproducts commonly used in the production of cements and concretes, such as fly ash and silica fume (370 Mt and $2 \mathrm{Mt}$ per year respectively (Amahjour, 2000)), it is clear that use of FC3R should be as a material that improves the final properties of the binder rather than causing a problem of final disposal. On the other hand, previous studies (Payá et al., 2003) have demonstrated that, owing to its high pozzolanic activity, the optimal dosage of FC3R as a cement substitute is in the range of $15-20 \%$. Addition above this level means that a certain excess amount of catalyst will exist that will not have available lime to react with; this excess will then be inert and cause a decrease in mechanical strength, since this substitution will have reduced the amount of cement.

Thermogravimetric analysis (TGA) is a useful tool to determine pozzolanic activity by means of lime fixation (Garcés et al., 2011; Pacewska et al., 2002; Payá et al., 2003, 2004), and studies of the mechanical strength of specimens of pozzolan-lime (De Weerdt et al., 2011), pozzolan-cement (Amin et al., 2011) and pozzolan-limestone-cement are useful for determining the optimum dosage (Payá et al., 2007), However, such analyses do not indicate the amount of pozzolan that remains unreacted. Cold hydrochloric acid $(\mathrm{HCl})$ treatment allows this determination to be made, and comparison of the results of this treatment with those from TGA therefore allows the optimal dosage conditions of pozzolan to be determined. 
This research studied the hydration behaviour of the FC3Rcement system. Lime fixation was determined by means of TGA and the progress of FC3R consumption due to pozzolanic reaction was measured by means of treatment using cold $\mathrm{HCl}$ attack of the cured pastes.

\section{Materials and experimental procedure}

The FC3R (supplied by BP Oil España S.A., Castellón, Spain) was ground for $20 \mathrm{~min}$ using a laboratory ball mill (Gabrielli Mill-2) in order to activate the pozzolanic behaviour of the catalyst (Payá et al., 1999). Ordinary Portland cement was used (Cemex, Valencia, Spain). The chemical compositions of FC3R and cement are summarised in Table 1. A water/binder ratio of 0.40 was selected for the pastes in this study, preparing a control paste (without spent catalyst) and a $15 \%$ substituted FC3R paste. Curing temperatures of 20 and $40^{\circ} \mathrm{C}$ were selected. The curing times tested for the $20^{\circ} \mathrm{C}$ curing temperature were $1,2,4,12$ and $24 \mathrm{~h}$ and 2, 3, 7, 14, 90 and 365 days. For the $40^{\circ} \mathrm{C}$ curing temperature, the curing times were $1 / 3,1,2,3,7,14$ and 28 days. After mixing, the pastes were kept in sealed plastic bottles and stored in a curing room at $100 \%$ relative humidity and $20^{\circ} \mathrm{C}$ or $40^{\circ} \mathrm{C}$. At each time of testing, the samples were manually ground in an agate mortar in the presence of acetone to stop the hydration and then dried for $30 \mathrm{~min}$ at $60^{\circ} \mathrm{C}$.

The TGA was performed in a Mettler-Toledo TGA850 module with a horizontal furnace; equipped with an ultramicro balance, it had a resolution of $0 \cdot 1 \mu \mathrm{g}$. The $100 \mu \mathrm{l}$ capacity crucibles used were made of aluminium, having a lid with a pin hole to obtain a self-generated atmosphere (Borrachero et al., 2008). The gas flow (nitrogen) for the surrounding atmosphere was $75 \mathrm{ml} / \mathrm{min}$. The heating rate was $10^{\circ} \mathrm{C} / \mathrm{min}$ in the range $35-600^{\circ} \mathrm{C}$.

The procedure used for cold $\mathrm{HCl}$ attack (Gomá and Vicente, 1999) was as follows. $2.5 \mathrm{~g}$ of hydrated sample was ground to obtain a powder with particles less than $63 \mu \mathrm{m}$ diameter (by sieving). This sample was mixed with $5 \mathrm{ml}$ of distilled water. This suspension was then added drop by drop to $300 \mathrm{ml}$ of $\mathrm{HCl}$ ( $10 \%$ by volume), keeping the temperature between 3 and $5^{\circ} \mathrm{C}$ and stirring for $30 \mathrm{~min}$. The residue was then filtered and dried.

Fourier transform infrared spectrophotometry (FTIR) qualitative studies were performed in a Mattson Genesis II FTIR in the range $400-4000 \mathrm{~cm}^{-1}$. The samples were observed by scanning electron microscopy (SEM) using a JEOL JSM-6300, equipped with energy dispersive X-ray microanalysis.

\section{Results and discussion}

\section{Thermogravimetric analysis}

Figure 1 shows the differential TGA curves (DTG) for the control (Figure 1(a)) and 15\% FC3R replacement cement (Figure 1(b)) pastes cured at $20^{\circ} \mathrm{C}$ for some of the curing times. Four main peaks can be observed. Peak 1 overlapped with peak 2 (100$180^{\circ} \mathrm{C}$ ), corresponding to the dehydration of calcium silicate hydrates (C-S-H) and ettringite (AFt). Peak $3\left(180-240^{\circ} \mathrm{C}\right)$ corresponds to the dehydration of calcium aluminate and aluminosilicate hydrates (C-A-H and C-A-S-H) of different composition. Peak $4\left(520-580^{\circ} \mathrm{C}\right)$ is due to the dehydroxylation of calcium hydroxide $(\mathrm{CH})$. The DTG curves are comparable within the same graph but are only qualitatively comparable between different graphs because the $y$-axis (not shown) is not the same. Peak 4 $(\mathrm{CH})$ appears after $12 \mathrm{~h}$ of curing; there is a drastic reduction in its intensity for the catalyst paste sample, suggesting the pozzolanic activity of the mineral addition FC3R.

The four main steps in cement hydration can be identified as (Hewlett, 1998)

the pre-induction period (first few minutes) with a rapid dissolution of ionic species

- initial production of hydrated phases

- $\mathrm{C}_{3} \mathrm{~A}$ hydration yields AFt with contribution of the ferrite phase

- reaction retarded due to the deposition of a layer of hydrated products at the cement grain surface.

The second period is the induction one (first few hours), characterised by a slowing down of the overall hydration rate. The concentration of $\mathrm{CH}$ in the liquid phase reaches its maximum and starts to decline. Termination of this stage is mainly due to nucleation of the second-stage C-S-H phase. This gives rise to initiation of the third stage (acceleration, 3-12 hours), controlled by the nucleation and growing of the hydrated products. The concentration of sulfate ions begins to diminish. Finally, the postacceleration period occurs, producing a gradual slowdown of the hydration rate, being controlled by diffusion.

According to this scheme, it can be concluded that, up until the fourth hour of curing time, the studied pastes are in the induction stage because only one peak appears at $1 \mathrm{~h}$, which is due to the overlapping of the dehydration of C-S-H and AFt and the first dehydration of calcium sulfate dehydrate, which is present in

\begin{tabular}{lrrrrrrrrr} 
Material & $\mathrm{SiO}_{2}$ & $\mathrm{CaO}$ & $\mathrm{Al}_{2} \mathrm{O}_{3}$ & $\mathrm{Fe}_{2} \mathrm{O}_{3}$ & $\mathrm{MgO}$ & $\mathrm{Na}_{2} \mathrm{O}$ & $\mathrm{K}_{2} \mathrm{O}$ & $\mathrm{SO}_{3}$ & LOI \\
\hline Cement & 19.9 & 63.69 & 5.4 & 3.62 & 2.14 & 0.10 & 1.17 & 3.66 & 2.0 \\
FC3R & 48.2 & $<0.01$ & 46.0 & 0.95 & $<0.01$ & 0.50 & $<0.01$ & 0.04 & 1.5
\end{tabular}

Table 1. Chemical composition (\%) 


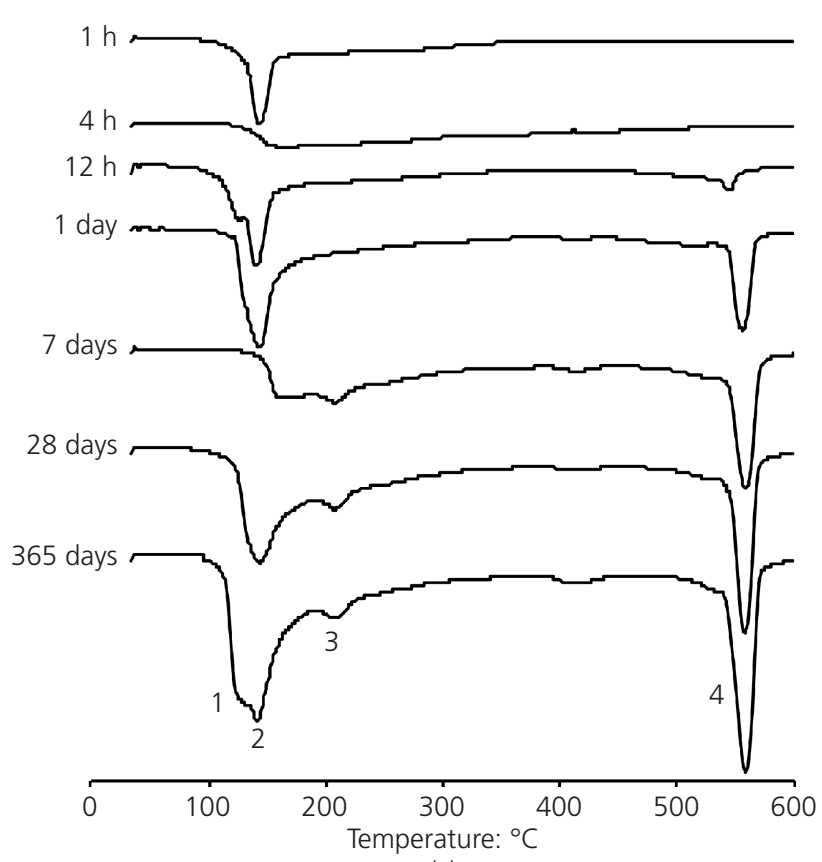

(a)

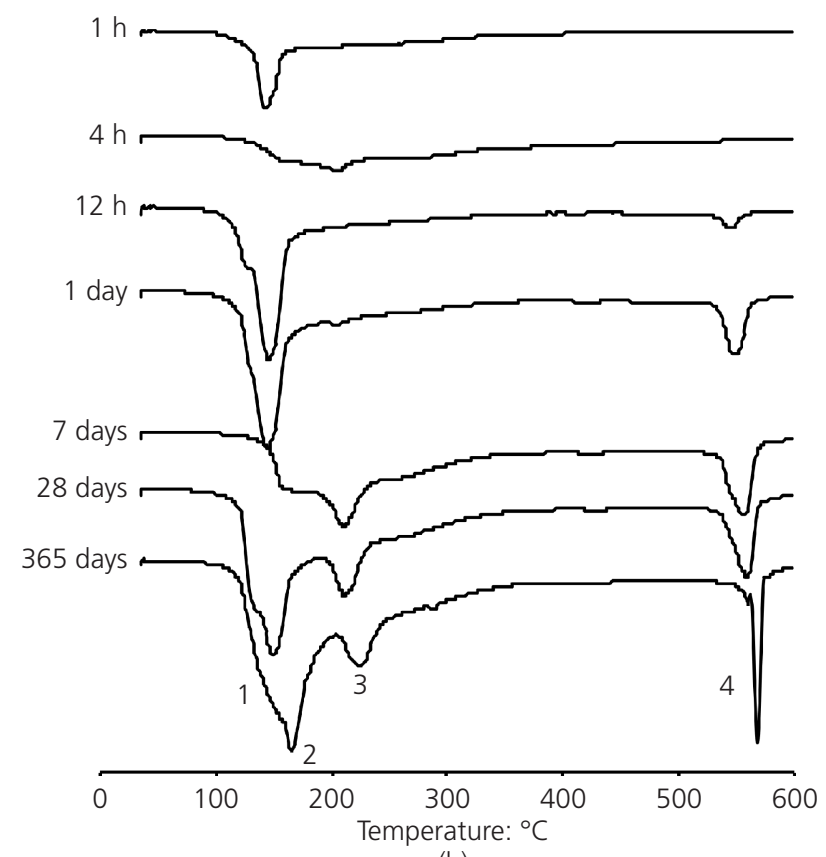

(b)

Figure 1. DTG curves of cement pastes for different curing times: (a) control; (b) 15\% FC3R

commercial cement as a setting regulator. The fourth hour of curing time seems to indicate the end of this period as a notable acceleration in hydration rate appears at 12 and $24 \mathrm{~h}$, as evidenced by the strong growth of the peaks belonging to C-S-H (peak 1), AFt (peak 2) and hydrated lime (peak 4). With regard to the dehydration of C-A-H and C-A-S-H (peak 3), this peak is more noticeable in the FC3R paste because the spent catalyst provides an extra source of aluminates.
Because one of the objectives of this work was to evaluate the pozzolanic activity of FC3R, the weight loss in stage 4 was used to calculate the percentage of fixed lime as

1. Fixed lime $(\%)=\frac{\left(\mathrm{CH}_{\mathrm{C}} \times C_{\%}\right)-\mathrm{CH}_{\mathrm{P}}}{\left(\mathrm{CH}_{\mathrm{C}} \times C_{\%}\right)} 100$

where $\mathrm{CH}_{\mathrm{C}}$ is the amount of $\mathrm{CH}$ in the control paste for a given curing time, $\mathrm{CH}_{\mathrm{P}}$ is the amount of $\mathrm{CH}$ in the pozzolan-containing paste at the same age and $C_{\%}$ is the cement fraction of the pozzolan-containing binder (in this case 0.85). Figure 2 shows the evolution of fixed lime with curing time (logarithmic scale; the raw data for this calculation are shown in Table 2).

Figure 2(a) shows the initial period (0-7 days) and Figure 2(b) shows the whole curing time range studied. This distinction was made because there are two main tendencies in lime fixation behaviour - one for the early ages (0-7 days) and another for longer curing times (7-365 days). Knowing that the initial cement hydration is strongly affected by the ettringite formation (which consumes lime) and that its rate is accelerated by the spent catalyst, it is possible to suppose that the behaviour could be different at early and later ages. In Figure 2, the correlation

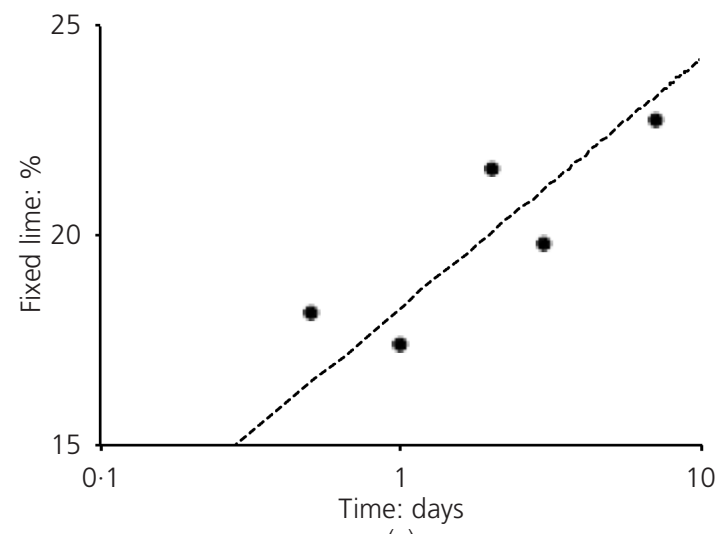

(a)

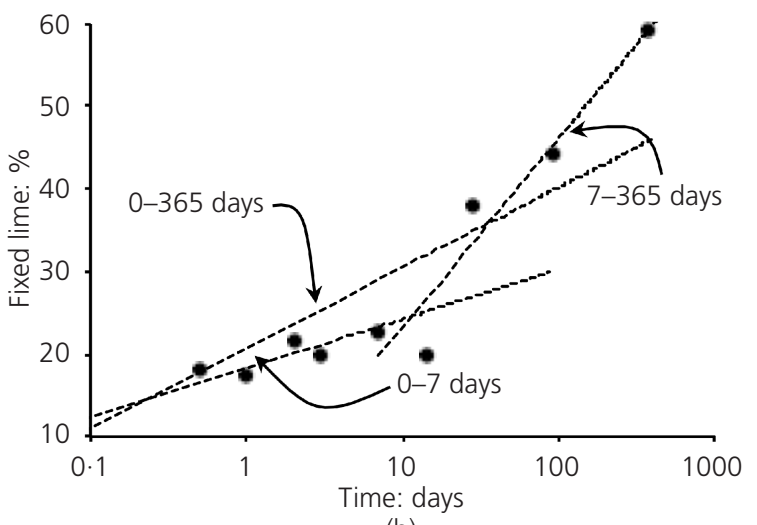

(b)

Figure 2. Percentage of fixed lime evolution with curing time for curing temperature of $20^{\circ} \mathrm{C}$ : (a) $0-7$ days; (b) $0-365$ days 


\begin{tabular}{|c|c|c|c|c|c|c|}
\hline Temperature, $T:{ }^{\circ} \mathrm{C}$ & Time, $t$ : days & $\mathrm{CH}_{C}(T, t): \mathrm{g}$ & $\mathrm{CH}_{\mathrm{P}}(T, t): \mathrm{g}$ & $P_{\mathrm{m}}(T, t): \mathrm{g}$ & $P_{r}(T, t): g$ & $\chi(T, t)$ \\
\hline \multirow[t]{9}{*}{20} & $1 / 2$ & 0.93 & 0.65 & $N D^{a}$ & ND & ND \\
\hline & 1 & $4 \cdot 86$ & $3 \cdot 41$ & $2 \cdot 50$ & 0.23 & $0 \cdot 10$ \\
\hline & 2 & $5 \cdot 18$ & $3 \cdot 45$ & ND & ND & ND \\
\hline & 3 & $5 \cdot 68$ & $3 \cdot 87$ & ND & ND & ND \\
\hline & 7 & $6 \cdot 94$ & $4 \cdot 55$ & ND & ND & ND \\
\hline & 14 & $7 \cdot 08$ & 4.83 & $2 \cdot 50$ & $0 \cdot 16$ & $0 \cdot 15$ \\
\hline & 28 & 8.52 & $4 \cdot 49$ & $2 \cdot 50$ & $0 \cdot 17$ & $0 \cdot 18$ \\
\hline & 90 & 8.63 & 4.09 & $2 \cdot 52$ & $0 \cdot 12$ & 0.17 \\
\hline & 365 & 11.01 & 3.83 & $2 \cdot 51$ & 0.05 & 0.20 \\
\hline \multirow[t]{7}{*}{40} & $1 / 3$ & $6 \cdot 16$ & $3 \cdot 75$ & $2 \cdot 51$ & 0.23 & $0 \cdot 10$ \\
\hline & 1 & 8.88 & 4.89 & $2 \cdot 49$ & $0 \cdot 20$ & 0.15 \\
\hline & 2 & $9 \cdot 47$ & 5.09 & $2 \cdot 50$ & $0 \cdot 12$ & $0 \cdot 16$ \\
\hline & 3 & $9 \cdot 88$ & $4 \cdot 48$ & $2 \cdot 50$ & $0 \cdot 13$ & $0 \cdot 16$ \\
\hline & 7 & $10 \cdot 67$ & 4.43 & $2 \cdot 50$ & 0.09 & $0 \cdot 18$ \\
\hline & 14 & 9.93 & 3.79 & $2 \cdot 51$ & $0 \cdot 10$ & 0.17 \\
\hline & 28 & $11 \cdot 15$ & $4 \cdot 28$ & $2 \cdot 50$ & 0.06 & 0.18 \\
\hline
\end{tabular}

\footnotetext{
a Not determined
}

Table 2. Raw data to calculate fixed lime (Equation 1) and the advance reaction (Equation 3)

between the percentage of fixed lime and curing time is shown (dashed lines) according to

\section{2. $\quad$ Fixed lime $(\%)=\alpha+\beta \ln t$}

The two first curing ages have been omitted because there were no hydrated lime decomposition signals on the TG curves. It is very probable that there was lime as a consequence of cement hydration, but it was probably consumed by the ettringite formation. The global correlation is shown in Figure 2(b). This underestimates the lime fixation at later curing times because the early-age data influence the correlation more strongly, again indicating that lime is consumed at the rate dictated by the ettringite formation. In the 7-365 day period, apart from ettringite formation, the hydrated lime is also consumed in C-S-H, $\mathrm{C}-\mathrm{A}-\mathrm{H}$ and C-A-S-H production. Table 3 lists the correlation parameters of Equation 2. The correlation coefficients of the individual periods are very good, but that obtained for the whole curing period is lower, as expected, since it attempts to correlate different hydration stages. The slope of the second period is about four times the slope of the first one, while the ordinate to the

\begin{tabular}{lrcc}
\hline Period: days & $\alpha$ & $\beta$ & $R$ \\
\hline $0-7$ & 18.28 & 2.59 & 0.99 \\
$7-365$ & 0.41 & 9.92 & 0.96 \\
$0-365$ & 20.80 & 4.21 & 0.89
\end{tabular}

Table 3. Correlation parameters of Equation 2 origin of the second period approaches zero. This behaviour suggests that there is no lime fixation at zero time (as expected), but the value of the ordinate for the first period is very high, since it takes in account the high lime fixation at very early ages. Obviously, the correlation of the whole range shows the average behaviour over the individual periods.

\section{Advance of the pozzolanic reaction}

Gomá and Vicente (1999) established a method to obtain the amount of oxides in a hydrated cement paste, as a modification of the ASTM C 1084-97 standard (ASTM, 1997). This method was used to determine the amount of reacted catalyst and therefore to evaluate the advance of the pozzolanic reaction. Under the method conditions, Gomá and Vicente confirmed that silica gel precipitation with the insoluble residue on cold $\mathrm{HCl}$ is avoided. The pure spent catalyst was also treated using this method. The result obtained after several tests was that there is a maximum dissolution of spent catalyst of $10 \%$, therefore this fact was taken into account in the calculation of the residue for the FC3Rcement pastes $(\phi)$. To ensure that the residue of the cementFC3R pastes was only spent catalyst, the residue yielded after $\mathrm{HCl}$ treatment on a sample cured for 90 days was examined by SEM. Figure 3(a) shows the micrograph obtained after $\mathrm{HCl}$ treatment (carbon coated to obtain the optimal conditions for the microanalysis). The microanalysis revealed that this is a spent catalyst particle. The silicon oxide and aluminium oxide contents are very similar to those found for spent FC3R. Moreover, it was concluded from this microanalysis that the calcium oxide content was lower than $0 \cdot 1 \%$. This same residue was analysed by FTIR and the spectrum is shown in Figure 3(b) compared with the FC3R spectrum: both spectra are almost identical. Knowing that 


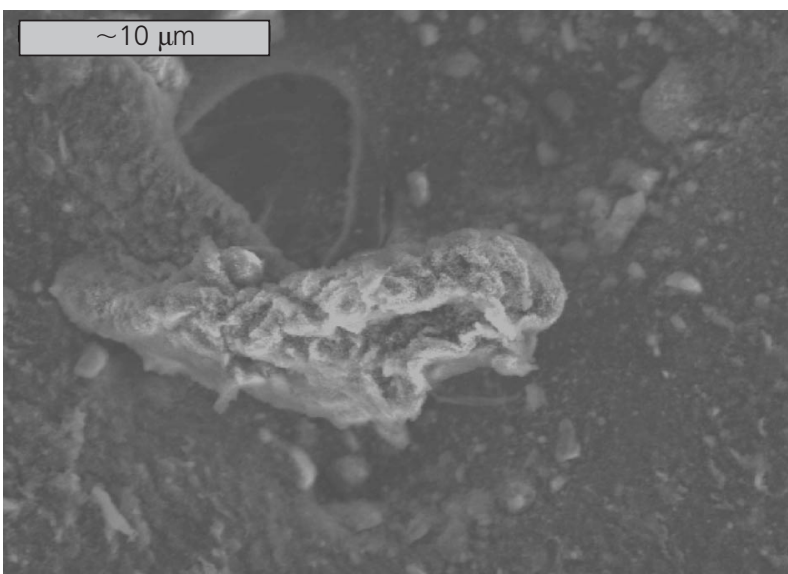

(a)

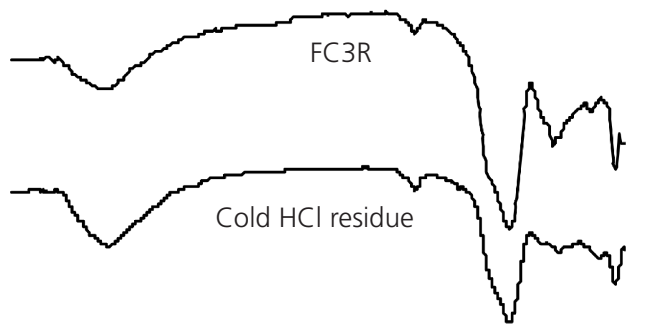

$\begin{array}{lllll}4400 & 3600 & \begin{array}{l}2800 \\ \text { Frequency: } \mathrm{cm}^{-1}\end{array} & 12000\end{array}$

(b)

Figure 3. Cold $\mathrm{HCl}$ residue of cement/FC3R paste cured for 90 days: (a) SEM; (b) FTIR spectrum

the residue was only spent catalyst, the advance of the pozzolanic reaction can be evaluated as

3.

$$
\begin{aligned}
\text { Advance reaction }(\%) & =\frac{\mathrm{FC} 3 \mathrm{R}_{\mathrm{Rx}}(\mathrm{g})}{\mathrm{FC} \mathrm{R}_{0}(\mathrm{~g})} 100 \\
& =\frac{\Psi\left[P_{\mathrm{m}}(1-\chi)\right]-\left(P_{\mathrm{r}} / \phi\right)}{\Psi\left[P_{\mathrm{m}}(1-\chi)\right]} 100
\end{aligned}
$$

where $\mathrm{FC}_{3} \mathrm{R}_{\mathrm{Rx}}$ and $\mathrm{FC}_{3} \mathrm{R}_{0}$ are the amount of spent catalyst reacted and the initial amount respectively, $P_{\mathrm{m}}$ and $P_{\mathrm{r}}$ are the amount of analysed sample and the amount of residue after $\mathrm{HCl}$ treatment respectively (in grammes), $\chi$ is the total weight loss calculated from the thermogravimetric curve of the paste (in fraction), $\phi$ is the amount (as a fraction) of spent catalyst not dissolved with cold $\mathrm{HCl}$ treatment, which takes values between 0.9 and 1 , and $\Psi$ is the fraction of cement substitution by pozzolan, which has a unique value of $0 \cdot 15$ in this study.

The advance reaction for the study at $20^{\circ} \mathrm{C}$ is shown in Table 4

\begin{tabular}{|c|c|c|c|c|}
\hline \multirow{2}{*}{$\begin{array}{l}\text { Time: } \\
\text { days }\end{array}$} & \multicolumn{2}{|c|}{ Advance reaction: \% } & \multirow{2}{*}{$\begin{array}{c}\text { Fixed } \\
\text { lime/FC3R } \\
\text { g/g }\end{array}$} & \multirow{2}{*}{$\begin{array}{c}\text { Fixed } \\
\text { lime/FC3R } \mathrm{R}_{\mathrm{Rx}} \\
(\phi=1): \\
\mathrm{g} / \mathrm{g}\end{array}$} \\
\hline & $\phi=0.9$ & $\phi=1.0$ & & \\
\hline 1 & $24 \cdot 21$ & $31 \cdot 79$ & 0.05 & $0 \cdot 15$ \\
\hline 14 & $45 \cdot 61$ & 51.05 & 0.08 & $0 \cdot 15$ \\
\hline 28 & $37 \cdot 85$ & $44 \cdot 07$ & $0 \cdot 18$ & 0.42 \\
\hline 90 & $58 \cdot 30$ & $62 \cdot 47$ & $0 \cdot 22$ & $0 \cdot 35$ \\
\hline 365 & $82 \cdot 92$ & 84.63 & $0 \cdot 37$ & 0.43 \\
\hline
\end{tabular}
(the raw data for this calculation are shown in Table 2). The
Table 4. Advance of the pozzolanic reaction and grammes of fixed lime per gramme of total spent catalyst and reacted spent catalyst; curing temperature $20^{\circ} \mathrm{C}$

ratios of grammes of fixed lime per grammes of initial spent catalyst and reacted catalyst are also listed as a function of curing time. Comparing the advance reaction with the fixed lime (Figure 2 ), it can be noticed that the former is always higher than the latter, indicating that $\mathrm{FC} 3 \mathrm{R}$ is the limiting reactive in these conditions. As mentioned, the factor $\phi$ in Equation 3 takes into account the spent catalyst that is dissolved in the cold $\mathrm{HCl}$ treatment. Knowing that a maximum of $10 \%$ is dissolved, but this FC3R fraction is not only the most soluble but is also the most reactive, so both advance reaction values are tabulated for $\phi=0.9$ and $\phi=1$. The values obtained for the grammes of fixed lime per gramme of reacted catalyst show that, at longer curing times, it is fixing about $1 \mathrm{~g}$ of lime for each $2 \cdot 3 \mathrm{~g}$ of catalyst reacted.

\section{Curing temperature influence}

Figure 4 shows the percentage of fixed lime for curing temperatures of 20 and $40^{\circ} \mathrm{C}$ as a function of curing time. The DTG curves of the $40^{\circ} \mathrm{C}$ study are not shown since their evolution was similar to the $20^{\circ} \mathrm{C}$ study (Figure 1) but, obviously, at $40^{\circ} \mathrm{C}$ the reaction rate was higher. In fact, the main difference was that the lime peak (peak 4 in Figure 1) was observed from $8 \mathrm{~h}$, while at

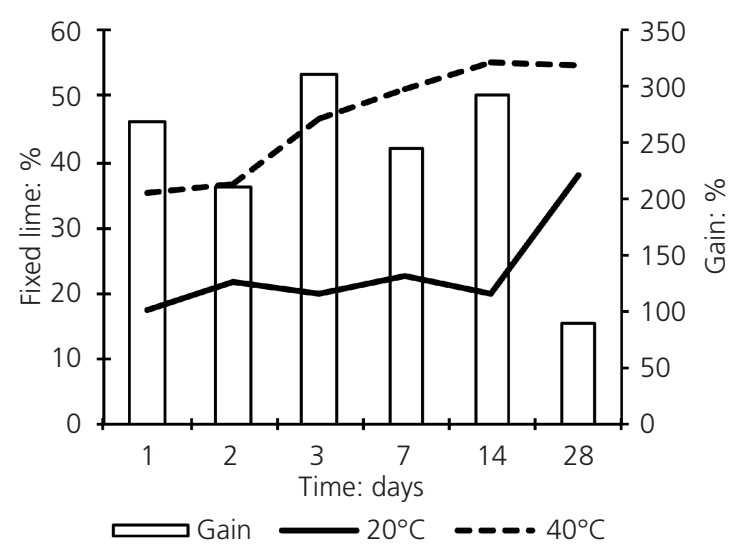

Figure 4. Percentage of fixed lime and gain of fixed lime evolution with curing time at 20 and $40^{\circ} \mathrm{C}$ 
$20^{\circ} \mathrm{C}$ it needed $12 \mathrm{~h}$ to appear. Also, the induction period was not notable, probably due to the high pozzolanic reaction rate. The increase in lime fixation when increasing the curing temperature from 20 to $40^{\circ} \mathrm{C}$ is remarkable, reaching at 28 days and $40^{\circ} \mathrm{C}$ the equivalent value of fixed lime of the paste cured for 365 days at $20^{\circ} \mathrm{C}$. The gain of lime fixed can be defined as

4. Gain $(\%)=\left(\frac{(\text { Fixed lime })_{40}{ }^{\circ} \mathrm{C}-(\text { Fixed lime })_{20}{ }^{\circ} \mathrm{C}}{(\text { Fixed lime })_{20} \mathrm{C}}\right) 100$

where fixed lime (at either 20 or $40^{\circ} \mathrm{C}$ ) is calculated with data from the third and fourth columns of Table 2 as $\left(\mathrm{CH}_{\mathrm{C}} \times 0 \cdot 85\right)-\mathrm{CH}_{\mathrm{P}}$.

Figure 4 shows that over 1-14 days there is a gain in the range of $210-310 \%$, with a reduction in gain at 28 days most likely due to exhaustion of the spent catalyst or the covering of these particles by hydration products. The percentage of fixed lime at $8 \mathrm{~h}$ was very high $(25 \cdot 3 \%$, not shown in Figure 4$)$, while after 7 days' curing time, it was barely modified (increase of about $4 \%$ in 21 days). Using the same model as the $20^{\circ} \mathrm{C}$ study (Equation 2), the percentage of fixed lime was correlated with the logarithm of curing time for the complete time range of the study

5. $\quad$ Fixed lime $40^{\circ} \mathrm{C}(\%)=38.8+4.5 \ln t$

which has a correlation factor $R=0 \cdot 97$. When comparing this equation with the results obtained for the $20^{\circ} \mathrm{C}$ study (see Table 3 ), the order of the slope is the same as that obtained for the complete period ( $0-365$ days), but the correlation factor is much better. This indicates that the paste cured at $40^{\circ} \mathrm{C}$ is in the acceleration and post-acceleration periods of hydration. On the other hand, the origin ordinate is much higher that the values obtained at $20^{\circ} \mathrm{C}$, since this parameter is clearly influenced by the high reactivity in the first few hours of curing.

Table 5 summarises the advance of the pozzolanic reaction obtained with the cold acid treatment. These results are much higher than the values obtained from the $20^{\circ} \mathrm{C}$ study (Table 4), as expected. For example, at 28 days, the advance at $40^{\circ} \mathrm{C}$ is approximately double that obtained at $20^{\circ} \mathrm{C}$ at the same age. In fact, the value obtained after 28 days' curing at $40^{\circ} \mathrm{C}$ is similar to that obtained after curing for 1 year at $20^{\circ} \mathrm{C}$. The values obtained for the grammes of fixed lime per gramme of initial spent catalyst and reacted catalyst are also shown in Table 5, which follow the same trend as the advance reaction when being compared with the data from the $20^{\circ} \mathrm{C}$ study (i.e. the 28 day $40^{\circ} \mathrm{C}$ value $(80.03 \%)$ is similar to the 1 year $20^{\circ} \mathrm{C}$ value $\left.(84.63 \%)\right)$. The ratio of grammes of fixed lime per gramme of reacted catalyst stays practically constant in the time period 3-28 days $(0.43-0.44)$, being similar to the established range at longer times at $20^{\circ} \mathrm{C}$ $(0 \cdot 43)$ (i.e. $2 \cdot 2-2 \cdot 3 \mathrm{~g}$ of fixed lime per gramme of reacted FC3R). The proposed methodology could thus help optimise the amount

\begin{tabular}{|c|c|c|c|c|}
\hline \multirow{2}{*}{$\begin{array}{l}\text { Time: } \\
\text { days }\end{array}$} & \multicolumn{2}{|c|}{ Advance reaction: \% } & \multirow{2}{*}{$\begin{array}{l}\text { Fixed } \\
\text { lime/FC } 3 R_{0}: \\
\quad g / g\end{array}$} & \multirow{2}{*}{$\begin{array}{c}\text { Fixed } \\
\text { lime/FC3R } \mathrm{R}_{\mathrm{Rx}} \\
(\phi=1): \\
\mathrm{g} / \mathrm{g}\end{array}$} \\
\hline & $\phi=0.9$ & $\phi=1.0$ & & \\
\hline $1 / 3$ & $25 \cdot 12$ & $32 \cdot 61$ & $0 \cdot 10$ & $0 \cdot 30$ \\
\hline 1 & $29 \cdot 45$ & $36 \cdot 51$ & $0 \cdot 18$ & 0.48 \\
\hline 2 & $57 \cdot 12$ & $61 \cdot 41$ & $0 \cdot 20$ & $0 \cdot 32$ \\
\hline 3 & $55 \cdot 21$ & $59 \cdot 69$ & $0 \cdot 26$ & 0.44 \\
\hline 7 & $66 \cdot 82$ & $70 \cdot 13$ & $0 \cdot 31$ & 0.44 \\
\hline 14 & $66 \cdot 35$ & $69 \cdot 71$ & 0.31 & 0.44 \\
\hline 28 & $77 \cdot 81$ & $80 \cdot 03$ & 0.35 & 0.43 \\
\hline \multicolumn{5}{|c|}{$\begin{array}{l}\text { Table 5. Advance of the pozzolanic reaction and grammes of } \\
\text { fixed lime per gramme of added and reacted catalyst; curing } \\
\text { temperature } 40^{\circ} \mathrm{C}\end{array}$} \\
\hline
\end{tabular}

of pozzolan that should be used in Portland cement mixtures to yield the maximum reaction degree.

\section{Conclusions}

- By means of thermogravimetric techniques, it has been shown that the induction period takes place in the first $4 \mathrm{~h}$ of curing and a clear acceleration exists between 12 and $24 \mathrm{~h}$, as evidenced by the growth in C-S-H-ettringite and lime peaks, as well as the appearance of C-A-H and C-A-S-H peaks.

- The percentage of fixed lime at $20^{\circ} \mathrm{C}$ was correlated with curing time over two periods ( $0-7$ days and 7-365 days) because, at the start of cement hydration, there is significant ettringite production, which consumes lime, as well as an acceleration in cement hydration caused by the catalyst.

- Cold $\mathrm{HCl}$ treatment was used to determine the advance reaction of the catalyst, which turned out to be much larger that the percentage of fixed lime, indicating that the spent catalyst in these conditions controls the pozzolanic reaction rate.

- The grammes of fixed lime per gramme of reacted catalyst indicated that approximately one part lime is chemically combined with 2.3 parts of spent catalyst reacted.

- The gain in fixed lime when elevating the curing temperature from 20 to $40^{\circ} \mathrm{C}$ is in the range of $210-310 \%$ at early curing ages (1-14 days). For longer curing times, exhaustion of the spent catalyst or covering of the FC3R particles by hydration products diminishes the reaction rate. The advance of the pozzolanic reaction at $40^{\circ} \mathrm{C}$ is much higher than at $20^{\circ} \mathrm{C}$. The final fixed lime/reacted FC3R ratio was $2 \cdot 3$ for the longest curing times at both temperatures studied.

- The combination of thermogravimetric techniques and cold $\mathrm{HCl}$ treatment allows determination of optimal dosage in order to maximise use of this excellent pozzolan.

\section{Acknowledgements}

This work was supported by Ministerio de Ciencia y Tecnología, Spain (Project MAT 2001-2694). Sergio Velázquez would like to 
thank the Consejo Nacional de Ciencia y Tecnología (CONACYTMéxico).

\section{REFERENCES}

Amahjour F (2000) Estudio de la reactividad de las puzolanas artificiales: Cenizas volantes y humo de sílice, y su reutilización en ingeniería civil. Doctoral thesis, Universidad Politécnica de Valencia, Valencia, Spain.

Amin N, Ali K, Shah MT and Alam S (2011) Chemical activation of bagasse ash in cement mortar. Advances in Cement Research 23(2): 89-95.

Antiohos SK, Chauliara E and Tsimas S (2006) Re-use of spent catalyst from oil-cracking refineries as supplementary cementing material. China Particuology 4(2): 73-76.

ASTM (1997) ASTM C 1084-97: Standard test method for Portland-cement content of hardened hydraulic-cement concrete. ASTM, West Conshohocken, PA, USA.

Borrachero MV, Payá J, Bonilla M and Monzó J (2008) The use of thermogravimetric analysis technique for the characterization of construction materials. The gypsum case Journal of Thermal Analysis and Calorimetry 91(2): 503509.

De Weerdt K, Sellevold E, Kjellsen KO and Justnes H (2011) Fly ash-limestone ternary cements: effect of component fineness. Advances in Cement Research 33(4): 203-214.

Garcés P, Glasser FP, Brew DRM, Zornoza E and Payá J (2011) Pozzolanic activity of a spent fluid catalytic cracking catalyst residue. Advances in Cement Research 23(3): 105-111.

Gomá FG and Vicente MD (1999) Chemical analysis of hardened concretes and mortars with active additions: a new procedure for its identification. Utilizing ready-mixed concrete and mortar. Proceedings of International Conference, Dundee,
UK (Dhir RK and Limbachiya MC (eds)). Thomas Telford, London, UK, pp. 313-322.

Hewlett PC (1998) Lea's Chemistry of Cement and Concrete, 4th edn. Arnold, London, UK.

Hsu KC, Tseng YS, Ku FF and Su N (2011) Oil cracking waste catalyst as an active pozzolanic material for superplasticizer mortars. Cement and Concrete Research 31(12): 18151820.

Meyers RA (1996) Handbook of Petroleum Refining Processes, 2nd edn. McGraw-Hill, New York, NY, USA.

Pacewska B, Bukowska M, Wilinska I and Swat M (2002) Modification of the properties of concrete by a new pozzolan. A waste catalyst from the catalytic process in a fluidized bed. Cement and Concrete Research 32(1): 145-152.

Payá J, Monzó J and Borrachero MV (1999) Fluid catalytic cracking catalyst residue (FC3R). An excellent mineral byproduct for improving early-strength development of cements mixtures. Cement and Concrete Research 29(11): 17731779.

Payá J, Monzó J, Borrachero MV and Velázquez S (2003) Evaluation of the pozzolanic activity of fluid catalytic cracking catalyst residue (FC3R). Thermogravimetric analysis studies on FC3R-Portland cement pastes. Cement and Concrete Research 33(4): 603-609.

Payá J, Monzó J, Borrachero MV and Velázquez S (2004) Chemical activation of pozzolanic reaction of fluid catalytic cracking residue (FC3R) in lime pastes. Part I: Thermal analysis. Advances in Cement Research 16(3): 123-130.

Payá J, Monzó J, Borrachero MV and Velázquez S (2007) The chemical activation of pozzolanic reaction of fluid catalytic cracking residue (FC3R) in lime pastes. Advances in Cement Research 19(1): 9-16.

\section{WHAT DO YOU THINK?}

To discuss this paper, please submit up to 500 words to the editor at www.editorialmanager.com/acr. Your contribution will be forwarded to the author(s) for a reply and, if considered appropriate by the editorial panel, will be published as a discussion in a future issue of the journal. 